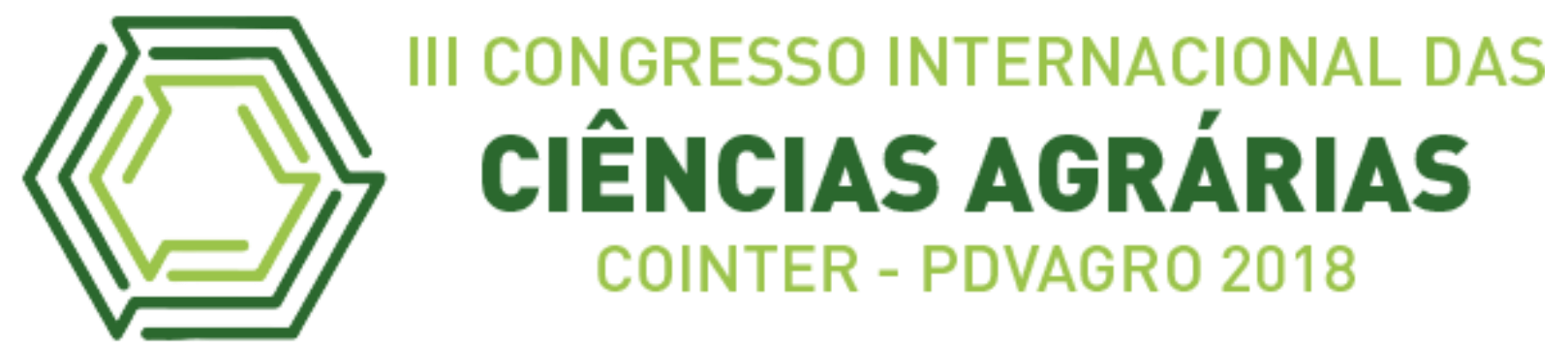

\title{
PRODUÇÃO DE DERIVADOS DA MANDIOCA E SUAS DIFICULDADES NO MUNICÍPIO DE BARCARENA, PARÁ
}

\section{PRODUCTION OF MANDIOCA DERIVATIVES AND THEIR DIFFICULTIES IN THE MUNICIPALITY OF BARCARENA, PARÁ}

\author{
Apresentação: Pôster \\ Alessandra dos Santos Santos ${ }^{1}$; Cinara Rafaela de Oliveira Neves ${ }^{2}$; Amanda da Silva \\ Nogueira $^{3}$; Ana Paula Macedo de Jesus ${ }^{4}$; Leonardo Elias Ferreira ${ }^{5}$
}

DOI: https://doi.org/10.31692/2526-7701.IIICOINTERPDVAGRO.2018.00626

\section{Introdução}

A mandioca (Manihot esculenta Crantz) é originária do continente Americano, principalmente da região Amazônica, tendo o Brasil como País de origem. No entanto, a África é de longe o continente de maior produção, a América Latina ocupa apenas o terceiro lugar, após o continente asiático (VILPOUX, 2008).

O cultivo da mandioca está associado ao Brasil desde o seu descobrimento, planta-se mandioca em todas as unidades da federação, e o produto tem destacada importância na alimentação humana e animal, além de ser utilizado como matéria-prima em diversos produtos industriais, é produzida principalmente por agricultores familiares, em sistemas de produção múltiplos, com pouco ou nenhum uso de tecnologia moderna, especialmente mecanização (SIVEIRO; SCHOTT, 2011).

De acordo com o Censo Agropecuário Brasileiro de 2017, a quantidade de mandioca produzida no Estado Pará é de 4.234.796 toneladas, sendo considerado o principal cultivo dos agricultores (IBGE, 2017). Sendo que destes, o município de Barcarena tem cerca de 20.000 toneladas de quantidade produzida de mandioca (IBGE,2017).

A região do Baixo Tocantins no Estado do Pará abrange os municípios de Abaetetuba, Acará, Baião, Barcarena, Cametá, Igarapé-Miri, Moju, Tailândia, Baião, Oeiras do Pará,

\footnotetext{
${ }^{1}$ Agronomia, Universidade Federal Rural da Amazônia, ale.eletrotecnica18@gmail.com

${ }^{2}$ Agronomia, Universidade Federal Rural da Amazônia, cinara.d.ferreira@gmail.com

${ }^{3}$ Agronomia, Universidade Federal Rural da Amazônia, amandanogueira26@hotmail.com

${ }^{4}$ Agronomia, Universidade Federal Rural Da Amazônia, paulamacedoj@outlook.com

${ }^{5}$ Dr., Fitotecnia, Universidade Federal Rural da Amazônia, Leonardo.ferreira@ufra.edu.br
} 
Limoeiro do Ajuru e Mocajuba. A farinha se constitui no principal produto produzido pelos agricultores familiares da região, porém não é um produto muito valorizado, sobretudo pela falta de uniformidade e padronização do produto, dificultando a comercialização para outras regiões e estados do País (JÚNIOR et al, 2009).

A partir da planta da mandioca, são obtidos diversos produtos tradicionalmente consumidos na maioria dos estados da região Norte do Brasil, como a farinha de mesa, o tucupi, a fécula, a farinha de tapioca e a maniva (JÚNIOR et al, 2016). A farinha de carimã ou puba é obtida da mandioca e vem sendo utilizada pela população na fabricação de pães, massas, bolos, biscoitos e mingaus, com o objetivo de substituir de forma parcial ou integral a farinha de trigo (PIMENTEL et al., 2001).

O município de Barcarena está localizado na mesorregião metropolitana de Belém, mais precisamente na microrregião de Belém (SILVA et al, 2017). Barcarena localiza-se no Estado do Pará e é um importante polo industrial Estadual, nele são realizados processos de industrialização, beneficiamento e exportação de matéria prima e principalmente de minério de caulim alumínio, a agricultura tradicional, por exemplo, foi a base da economia da cidade por várias décadas (BARCARENA, 2013).

Em Barcarena, a maioria da população é de origem cabocla, nascida e criada no lugar, cuidam de árvores frutíferas, desenvolvem a agricultura rudimentar de macaxeira e mandioca e, em função deste produto, erguiam casas de farinha e escavavam poços de água, da mandioca, além do fabrico de farinhas, eles obtém o tucupi e a tapioca, todos integrando a sua dieta alimentar (NAHUM, 2008).

O objetivou-se com este trabalho analisar quantos produtos derivados da mandioca são produzidos pelos produtores rurais e diagnosticando os problemas enfrentados pelos mesmos no município de Barcarena na região do Baixo Tocantins no Estado do Pará.

\section{Fundamentação Teórica}

No Brasil, ainda existem muitas comunidades que dependem fortemente da mandioca e da sua farinha para sobrevivência seu cultivo é explorado sob o ponto de vista comercial e como cultura de subsistência. A conservação de diferentes variedades é valorizada pelos grupos de agricultores, dadas as diferenças nutricionais de cada cultivar. Alguns produtos derivados da mandioca elaborados pelos índios e logo conhecidos pelos portugueses foram: mbeu (produto semelhante ao atual beiju); mambeca (ancestral do pirão); poqueca; curuba; cica; e puba (SEBRAE, 2008). 
No Estado do Pará, mais de $90 \%$ da produção de raiz de mandioca é transformada em farinha de mesa, durante o processo de fabricação da farinha, as raízes de mandioca-brava de polpa amarela são trituradas e prensadas para a remoção de um líquido denominado de manipueira, o qual é gerado na razão de 300 L por cada mil quilos de raízes processadas (FERREIRA et al., 2001)

\section{Metodologia}

Foram realizados levantamentos bibliográficos sobre o Município de Barcarena e o tema em questão, através desta pesquisa foi elaborado um questionário com perguntas abertas e fechadas objetivando uma pesquisa de caráter quanti-qualitativo. O presente estudo foi realizado na comunidade do Cafezal, pertencente ao município de Barcarena. A escolha desse município se deu devido ao fato da economia local ter base tradicional na Agricultura. Os questionários abordaram informações sobre a produção da mandioca, os produtos derivados e as dificuldades enfrentadas por esses produtores.

Foram entrevistados 23 produtores rurais que cultivam a mandioca. Dessa forma, para a análise dos dados obtidos, usou-se a estatística descritiva, afim de analisar os aspectos sociais e econômicos. Os dados coletados foram agrupados em planilha do Microsoft Office Excel 2013 e representados por meio de gráficos e tabelas os quais serviram de base para análise e interpretações.

\section{Resultados e Discussões}

Com a aplicação dos questionários, pode-se conhecer mais detalhadamente a realidade da comunidade, e a partir daí foi possível gerar os resultados a serem apresentados nesse trabalho. A mandioca é produzida por $100 \%$ dos produtores, cerca de $87 \%$ destes consomem e comercializam a farinha, sendo que $13 \%$ apenas a consomem, isto é, não usam da farinha como produto de comercialização (Figura 1).

Figura 1: Análise da identificação de Produção da mandioca e comercialização de farinha dos produtores do Município de Barcarena, PA. Fonte: Própria 


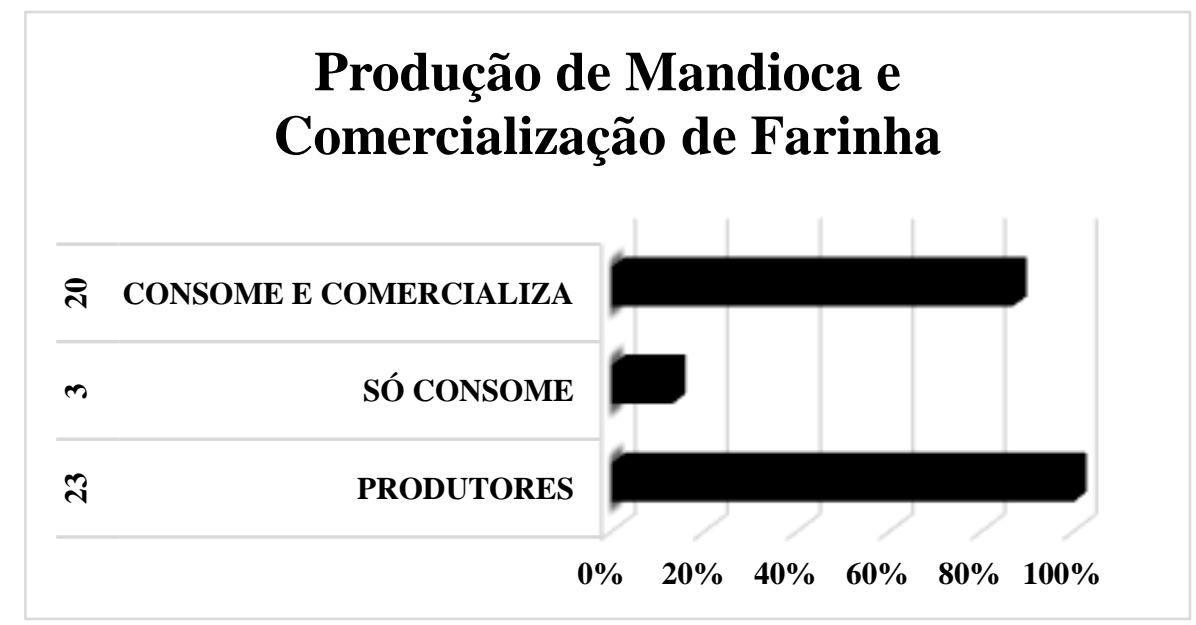

Identificou-se como produtos derivados da mandioca produzidos na região: farinha, goma, tucupi, tapioca e carimã, utilizados tanto para consumo como para comercialização. Enquanto que apenas a macaxeira é destinada somente para consumo. Na qual, 95,65\% dos entrevistados produzem farinha, e destes cerca de $86,65 \%$ realizam sua comercialização e consumo (Tabela 1). Como evidenciou (CHISTÉ; COHEN, 2006) que dentre os muitos subprodutos obtidos da mandioca, a farinha é considerada o principal produto, absorvendo cerca de 70 a $80 \%$ da produção mundial da raiz.

A macaxeira e o carimã são produzidos e consumidos por apenas 4,34\% dos produtores, demonstrando um baixo percentual comparado com os da farinha, em contrapartida tucupi e goma representaram uma comercialização de 34,78\% e 26\% respectivamente (Tabela 1$)$.

\begin{tabular}{ccc}
\hline $\begin{array}{c}\text { Produtos Derivados da } \\
\text { Mandioca }\end{array}$ & $\begin{array}{c}\text { Produção } \\
(\boldsymbol{\%})\end{array}$ & $\begin{array}{c}\text { Comercialização } \\
(\boldsymbol{\%})\end{array}$ \\
\hline Farinha & $95,65 \%$ & $86,95 \%$ \\
\hline Tucupi & $34,78 \%$ & $30,44 \%$ \\
\hline Goma & $26 \%$ & $21,74 \%$ \\
\hline Tapioca & $30,43 \%$ & $35 \%$ \\
\hline Macaxeira & $4,34 \%$ & 0 \\
\hline Carimã & $4,34 \%$ & $5 \%$ \\
\hline
\end{tabular}

Tabela 1: Produtos Derivados da Mandioca $(n=23)$. Fonte: Própria 
Komarcheski e Denardin (2013), constataram que o transporte é um dos problemas que dificultam a comercialização de farinha. Pode-se observar que referente aos $86,95 \%$ dos entrevistados que consomem e comercializam a farinha, destes , 80\% relataram que sua maior dificuldade hoje na produção de mandioca é transporte, isso se dá devido ao fato desses produtores não terem como escoar a safra por conta própria e precisarem pagar preços irrisórios para atravessadores ou alugar transportes para fazer a distribuição da produção, e isso é representado em $15 \%$ nas dificuldades relacionadas a custo, além da falta de mecanização nas etapas de produção da mandioca, para o preparo do solo e nos tratos culturais, o que segundo eles ajuda na elevação dos custos de produção (Figura 2).

Figura 2: Análise da identificação das dificuldades encontradas pelos produtores de farinha do Município de Barcarena, PA. Fonte: Própria

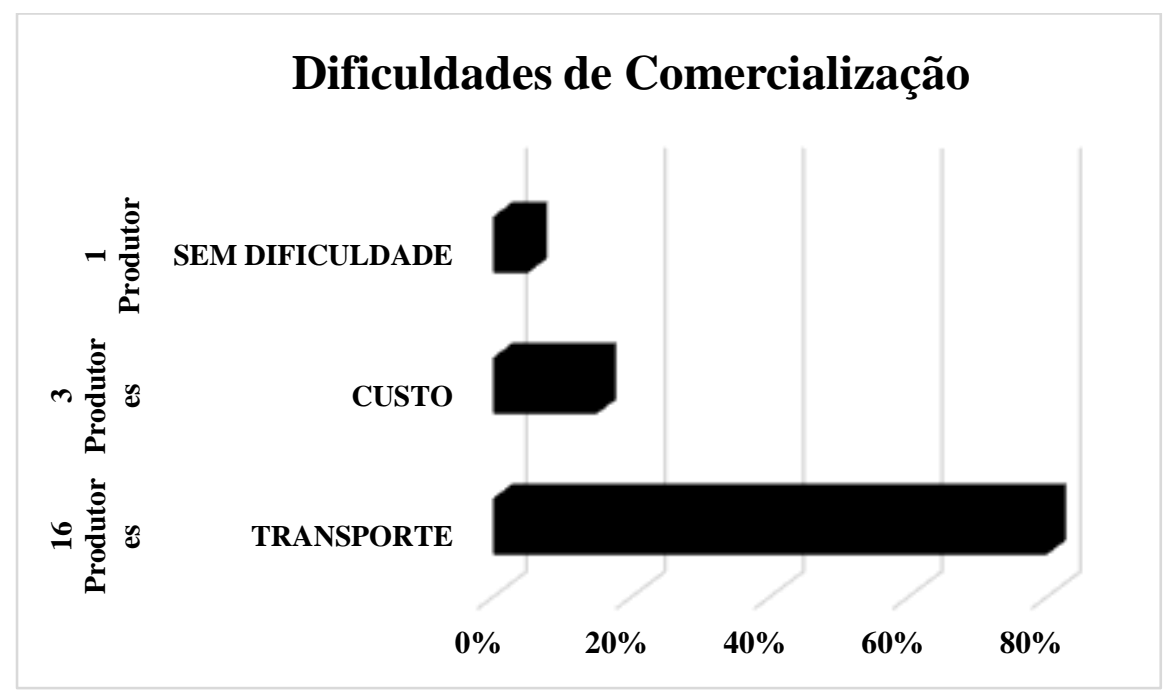

\section{Conclusões}

Com base nos dados do presente trabalho pode-se concluir que, a farinha é o derivado da mandioca de maior produção e comercializada nessa região, e o tucupi representa uma porcentagem significativa de produção e comercialização. A maior dificuldade enfrentada por esses produtores é o transporte, e a falta de mecanização é a segunda maior dificuldade e gera um maior custo com, preparo do solo e tratos culturais realizados na área durante o ciclo de produção.

Diante disso, há necessidade de intervenções com políticas públicas acessíveis a estes produtores ou até mesmo a inclusão deles em associações, garantindo que não haja 
dificuldades com transportes e consequentemente que não gere custos na produção.

\section{Referências}

CHISTÉ, Renan Campos; COHEN, Kelly de Oliveira. Efeito do Processo de Fabricação da Farinha de Mandioca. Embrapa Amazônia Oriental Documentos (INFOTECA-E), 2006

ESTUDO DE MERCADO, SOBRE A MANDIOCA (FARINHA E FÉCULA), Sebrae. 2008. Disponivel em: <http://atividaderural.com.br/artigos/5602f3e181880.pdf. >Acesso em: 05 out 2018.

FERREIRA, W. de A.; BOTELHO, S. M.; CARDOSO, E. M. R. Manipueira: um adubo orgânico em potencial. Belém, PA: Embrapa Amazônia Oriental, 2001. 21 p. (Embrapa Amazônia Oriental. Documentos, 107)

IBGE. Censo Agropecuário 2017: Produção de Lavouras Temporárias. Cidades: Barcarena. Disponível em: <https://cidades.ibge.gov.br/brasil/pa/barcarena/pesquisa/14/0 >. Acesso em: 15 set. 2018.

IBGE. Censo Agropecuário 2017: Produção de Lavouras Temporárias. Estado: Pará. Disponível em: https://cidades.ibge.gov.br/brasil/pa/pesquisa/14/0. Acesso em: 15 set. 2018.

JUNIOR, MODESTO et al. Produtividade de mandioca de agricultores familiares do baixo Tocantins, Pará. In: Embrapa Amazônia Oriental-Artigo em anais de congresso (ALICE). Revista Raízes e Amidos Tropicais, Botucatu, v. 5, p. 522-528, jul. 2009., 2009.

JÚNIOR, Modesto et al. Cultura da mandioca: aspectos socioeconômicos, melhoramento genético, sistemas de cultivo, manejo de pragas e doenças e agroindústria - Embrapa, 2016. Disponível em: http://www.univale.br/sites/biblioteca/biblioteca_online_agronegocio/livrosbiblioteca/CULT URA\%20DA\%20MANDIOCA.pdf>. Acesso em: 25 set. 2018.

KOMARCHESKI, R; DENARDIN. V.F.Sustentabilidade socioambiental da produção de farinha de mandioca em Guaraqueçaba - PR. 2013. Paraná. Disponível em:< https://acervodigital.ufpr.br/bitstream/handle/1884/29349/R\%20-\%20D\%20-

$\%$ 20ROSILENE\%20KOMARCHESKI.pdf? sequence=1\&isAllowed=y >. Acesso em: $15 \mathrm{de}$ Out. 2018.

NAHUM, João Santos. USOS DO TERRITÓRIO, MODERNIZAÇÃO E AÇÕES POLÍTICAS CONSERVADORAS EM BARCARENA-PA. Geosul, Florianópolis, v. 23, n. 45, p 65-84, jan./jun. 2008

PIMENTEL, Flávio Araújo; DE OLIVEIRA, Solange Maria Gadelha; DAMASCENO, Márcio Jander Ribeiro. Processamento de farinha de carimã. Embrapa Acre-Circular Técnica (INFOTECA-E), 2001.

PREFEITURA MUNICIPAL DE BARCARENA - PMB. Disponível em: < http://www. barcarena.pa. gov.br/>, PMB, 2013. Acesso em: 21 set. 2018. 
SILVA, Christian et al. Uso do território e implicações socioterritoriais da mineração no Município de Barcarena (Pará-Brasil): População, arrecadação e segurança pública. ESPACIOS,2017. Disponível em:

http://www.revistaespacios.com/a17v38n06/a17v38n06p24.pdf >. Acesso em: 15 Out. 2018.

SIVIERO, Amauri; SCHOTT, Bianca. CARACTERIZAÇÃO BOTÂNICA E AGRONÔMICA DA COLEÇÃO DE MANDIOCA DA EMBRAPA ACRE. Revista Raízes e Amidos Tropicais, v. 7, n. 1, p. 31-41, 2011.

VILPOUX, Olivier François. Competitividade da mandioca no Brasil, como matéria prima para amido. Informações Econômicas, v. 38, n. 11, p. 27-38, 2008. 